\title{
PANDEMIA, PERIFERIAS E AS FORMAS ELEMENTARES DA VIDA SOCIAL
}

PANDEMIC, URBAN PERIPHERIES AND THE ELEMENTARY FORMS OF SOCIAL LIFE

Leonardo Fontes

Doutor em Sociologia pelo Instituto de Estudos Sociais e Políticos da Universidade Estadual do Rio de Janeiro (IESP/UERJ), pesquisador de pós-doutorado no International Interdisciplinary Postdoctoral Program do Centro Brasileiro de Análise e Planejamento (IPP/CEBRAP), bolsista da Fundação de Amparo à Pesquisa do Estado de São Paulo (Fapesp) pelo processo no 2019/13125-2. 


\section{RESUMO}

O objetivo deste artigo é discutir os potenciais das redes de solidariedade formadas por moradores de bairros periféricos no contexto da pandemia de Covid-I9 em termos de mobilização coletiva, elaboração de questões públicas e construção de laços comunitários. O texto aponta o impacto desigual da pandemia e das consequências políticas, econômicas e sociais que afetaram sobremaneira aqueles que vivem nas periferias urbanas, tanto a partir de dados quantitativos quanto no que se refere à percepção de lideranças comunitárias. Ao apontar a emergência de inúmeras iniciativas de apoio mútuo entre moradores periféricos, argumenta-se que elas podem servir de base para formas de sociabilidade que se contraponham ao utilitarismo individualista que sustenta o discurso e as práticas políticas emanadas a partir do governo Bolsonaro. A pesquisa está baseada em fontes secundárias e em entrevistas e depoimentos coletados pelo autor e por membros da Rede de Pesquisa Solidária, ao longo de 2020.

Palavras-chave: pandemia; periferias urbanas; problemas públicos; ação coletiva.

\section{ABSTRACT}

This article discuss the potentials of the solidarity networks formed by residents of peripheral neighborhoods in the context of the Covid-I9 pandemic. These potentials will be analyzed in terms of collective mobilization, elaboration of public issues, and strengthening of community bonds. The paper highlights the Covid-I9 pandemic's unequal impact and its political, economic, and social consequences to urban peripheries dwellers, both from quantitative data and concerning the perception of communitarian leaders. In pointing out the emergence of numerous initiatives of mutual support among peripheral residents, it is argued that they can serve as a basis for a sociability opposed to the utilitarian individualism perspective that sustains the discourse and political practices emanating from the Bolsonaro government. The research is based on secondary sources data, interviews and testimonies collected by the author and members of the Solidarity Research Network throughout $202 \mathrm{O}$.

Keywords: pandemic; urban peripheries; public problems; collective action. 


\section{Introdução}

Este artigo busca analisar os potenciais que os processos de ajuda mútua e solidária organizados por e para moradores de áreas urbanas periféricas podem vir a ter para mobilização coletiva, elaboração de questões públicas e construção de laços comunitários. Para além desses potenciais, o texto advoga a hipótese de que essas iniciativas de apoio mútuo podem servir de base para uma sociabilidade que se contraponha, em termos de práticas cotidianas entre moradores de periferias urbanas, ao utilitarismo individualista que sustenta o atual discurso do governo federal.

Durou pouco a sensação de que a pandemia de Covid-I9 afetaria mais os ricos do que os pobres no Brasil. Mesmo a ideia de que a pandemia seria "democrática" ao impactar igualmente os moradores de todas as regiões do país ou de uma mesma cidade, não sobreviveu a alguns meses de teste empírico após a chegada do novo coronavírus por aqui. A vulnerabilidade socioeconômica, a impossibilidade de praticar o isolamento social, a assimetria de informações e a dificuldade de acesso a determinados direitos fez com que os efeitos da pandemia sobre os mais pobres, em especial os moradores de bairros periféricos nas cidades, fossem muito mais devastadores comparativamente às classes médias e altas.

Em grande parte, os vulneráveis se tornaram ainda mais vulneráveis devido à postura adotada pelo governo federal. Desde o início do mandato, e com mais intensidade após a chegada do novo coronavírus ao Brasil, o presidente Jair Bolsonaro deixou claro seu "apreço à autonomia dos indivíduos como superior ao bem-estar coletivo" (ALONSO, 2020, on-line). Com relação à pandemia, Bolsonaro defendeu que nada poderia fazer a seu respeito, uma vez que "70\% [dos brasileiros] vai pegar o vírus". Diante dessa realidade supostamente inescapável, a preocupação primordial do país deveria ser com a economia, de modo a evitar que o Estado "atrapalhasse" a livre iniciativa empreendedora e o bom funcionamento dos mercados por meio de medidas de restrição de circulação ou de fechamento de atividades comerciais. Com isso, "Bolsonaro exclui a solidariedade de sua cesta de valores" (ALONSO, 2020, on-line).

Ainda que seja possível, como faz Alonso (2020), encontrar traços do pensamento de Hobbes e Locke nas ideias advogadas pelo atual presidente, o liberalismo adotado por Bolsonaro e seu ministro da economia, Paulo Guedes, se filia muito mais ao libertarianismo econômico ou ao neoliberalismo de Herbert Spencer, e posteriormente desenvolvido por autores como Ludwig von Mises, Friedrich Hayek, ${ }^{1}$ entre outros, como bem aponta

\footnotetext{
${ }^{1}$ Para um detalhamento dessa corrente neoliberal de pensamento e suas implicações sociais e políticas, ver Foucault (2008) e Dardot e Laval (2016).
} 
Lynch (202I). Essa corrente de pensamento teria surgido "como reação ao processo de democratização política, impulsionado pelo socialismo e pelo alargamento do sufrágio" e "consiste em um híbrido de liberalismo e conservadorismo" (LYNCH, 2O2I, on-line).

Nas periferias urbanas, foco da análise deste texto, esse discurso chega por meio da "matriz discursiva" do "empreendedorismo monetarista de parcelas do mundo popular" (FELTRAN, 2020, on-line). ${ }^{2} \mathrm{O}$ discurso em torno do empreendedorismo e da empregabilidade há tempos vem substituindo a ótica da informalidade para lidar com os problemas de inclusão social dos mais pobres no mercado de trabalho (MACHADO DA SILVA, 2002). Bolsonaro, no entanto, radicalizou esse discurso, e durante a pandemia, agiu de modo bastante coerente com ele.

Fugiria ao escopo deste texto alongar-se demasiadamente por esse tema. O intuito aqui é apontar um traço fundamental do discurso e da prática desse neoliberalismo bolsonarista: o individualismo utilitarista. Por essa lógica de pensamento, comum a muitos autores das ciências econômicas e sociais, a sociedade seria formada por indivíduos racionais que agem em busca da maximização da utilidade para si. Com isso, afirma-se que é possível relacionar os fenômenos sociais exclusivamente com decisões e cálculos dos indivíduos, e que a única maneira de compreender a ação individual é entendê-la como interessada e racional e, em última instância, egoísta (CAILLÉ, 2002). Coerente com essa linha de pensamento, deveria caber aos indivíduos decidirem se tomam ou não vacinas, se usam ou não remédios sem eficácia comprovada para a doença e se preferem correr o risco de morrer de fome ou de Covid-I9.

O discurso propalado pelo governo federal reforça, portanto, essa lógica individualista já bastante difundida entre parte dos setores populares das grandes cidades. Este artigo, no entanto, pretende olhar para o outro lado dessa história. Se é fato que existe uma adesão significativa ao discurso do empreendedorismo e do utilitarismo nas periferias urbanas, existe também mobilização coletiva, luta por direitos e construção de laços comunitários. Partindo de um referencial teórico pragmatista (CEFAÏ, 20I7a,b; BOLTANSKI, 2OII, 20I6; BOLTANSKI; THÉVENOT, I999) e antiutilitarista (GODBOUT; CAILLÉ, I999; CAILLÉ, 2002), será argumentado que a pandemia se configurou como uma "situação problemática" que foi problematizada e transformada em um "problema público" a partir da experiência coletiva daquele problema. Dessa experiência surgiram ou foram reforçadas "arenas públicas" que passaram a atuar e reivindicar políticas que atacassem esses problemas coletivos.

\footnotetext{
${ }^{2}$ Além dessa, Feltran enxerga outras duas matrizes discursivas presentes no bolsonarismo popular: o militarismo das Forças Armadas e das polícias militares, e o anti-intelectualismo evangélico.
} 
O texto se divide em mais quatro partes além desta introdução e das considerações finais. Na segunda seção, será desenhado o quadro mais estrutural em que são apontados alguns dos principais problemas que afetaram as periferias urbanas ao longo do último ano, desde que a pandemia chegou ao Brasil. Os dados utilizados nesta parte vêm sobretudo de fontes secundárias de outas pesquisas que se debruçaram sobre diversos impactos da pandemia do novo coronavírus no Brasil.

Na terceira seção, será apresentada a visão de lideranças comunitárias de periferias urbanas a respeito dos principais problemas que suas regiões enfrentaram ao longo do último ano, buscando cruzar percepções qualitativas dos moradores com os dados quantitativos apresentados na seção anterior. A análise nesta seção está baseada em dados coletados pela Rede de Pesquisa Solidária, ${ }^{3}$ que se formou no início de 2020, com a qual este autor tem colaborado.

Na quarta seção, será desenvolvida uma reflexão a respeito da resposta que os moradores das regiões periféricas desenvolveram em termos de iniciativas coletivas, como a arrecadação de doações, e a distribuição de cestas básicas e de kits de higiene para as famílias mais pobres e afetadas pela crise econômica e sanitária. Os dados apresentados se baseiam em relatos coletados por este autor a partir de conversas virtuais e trocas de mensagens com moradores de duas regiões da periferia de São Paulo onde pesquisas sobre economia, política e sociabilidade são realizadas pelo autor desde 2015, além de dados das pesquisas da Rede de Pesquisa Solidária.

A última seção traz as considerações finais e busca apontar os potenciais que essas ações de solidariedade e apoio comunitário têm no sentido de identificar questões públicas e ampliar a mobilização coletiva na luta por direitos - sobretudo no que se refere à capacidade dessas iniciativas de construir, na prática, alternativas de sociabilidade e de uma "gramática da dádiva", ${ }^{4}$ que se contrapõem ao utilitarismo individualista que impera no discurso presidencial, mas também de moradores das áreas periféricas da cidade.

\section{Desigualdades pandêmicas: sobreposição de crises e uma nova situação problemática}

Desde meados de 2020, diversas pesquisas têm apontado os efeitos desiguais provocados pela chegada e pela disseminação do novo coronavírus ao Brasil. Para os

\footnotetext{
${ }^{3}$ Para mais detalhes, ver: <https://redepesquisasolidaria.org/>.

4 Utilizarei neste texto o termo "dádiva" em vez de "dom" para fazer referência à forma como ficou mais difundida a tradução brasileira do clássico de Marcel Mauss (2013). O uso intercambiável dos termos por outros autores ou traduções não altera, contudo, seu sentido.
} 
interesses deste texto, esses efeitos serão agrupados em quatro grandes blocos de questões que, do ponto de vista quantitativo e qualitativo, emergiram de maneira enfática para os habitantes das periferias urbanas como problemas decorrentes da atual crise: I) saúde; 2) economia, que envolve questões ligadas a trabalho, renda e segurança alimentar; 3) dificuldade de acesso à educação; 4) violação de outros direitos humanos.

A pandemia e as questões decorrentes dela abordadas neste texto serão interpretadas como uma "situação problemática". Uma situação torna-se problemática quando as reações habituais a determinado ambiente já não proporcionam a satisfação de necessidades e desejos dos envolvidos, demandando, portanto, novas práticas e ações com o objetivo de se adequar à nova estrutura social ou de modificá-la. Em uma situação problemática, cujas consequências são percebidas e avaliadas coletivamente como negativas, "as pessoas se inquietam, se interrogam, investigam, experimentam, discutem" (CEFAÏ, 20I7a, p. I88) de modo a problematizá-la e lhe dar publicidade.

Mesmo estando na origem dos problemas atuais, as questões ligadas à saúde pública levaram algumas semanas, desde a chegada da doença no Brasil, para atingir os moradores das periferias urbanas. Hoje, no entanto, as regiões periféricas são impactadas de maneira muito mais intensa do que as áreas centrais, onde a pandemia desembarcou primeiro.

Os dados mais recentes da pesquisa do Projeto SoroEpi MSP $2,{ }^{5}$ de janeiro de 2O2I antes, portanto, da explosão mais recente de casos e mortes e do início da vacinação no país - apontam que, no município de São Paulo, 29,9\% da população adulta já tinha anticorpos contra o SARS-CoV-2, ou seja, havia sido contaminada em algum momento pelo vírus. No entanto, entre os que tinham renda familiar de até $R \$ 2.200$, esses números chegavam a $37,9 \%$. Do mesmo modo, entre aqueles que declararam raça/cor de pele parda e preta, os já contaminados estavam em 37,8\%. Assim, em relação à raça/cor de pele, a soroprevalência era maior I,6 vezes entre as pessoas que se autodeclararam pretas e pardas quando comparada às brancas $(37,8, \%$ versus $23,2 \%)$. Além disso, indivíduos com nível de escolaridade até o ensino fundamental apresentaram soroprevalência maior em I,7 vezes em comparação com indivíduos com nível superior completo (33,8\% versus 19,6\%). Ao analisar a evolução da doença, é possível notar que o ritmo de contaminação entre os mais pobres segue mais intenso. Entre outubro e janeiro, a presença de anticorpos contra o novo coronavírus no estrato mais rico passou de $21,6 \%$ para $22,8 \%$, e no mais pobre, de $30,4 \%$ para $36,4 \%$.

\footnotetext{
${ }^{5}$ O projeto realiza a coleta de sangue e o exame de anticorpos para Covid-19 de forma amostral entre moradores da capital paulista. Até o momento, foram concluídas cinco etapas da pesquisa, sendo a mais recente com dados coletados entre 14 e 23 de janeiro 2021. Mais detalhes podem ser encontrados em: <https://www.monitoramentocovid19.org/resultados>.
} 
Em outro exercício, uma equipe de pesquisadores do LabCidade e do Instituto Polis (MARINO et al., 2020) apontou uma forte associação entre os locais que mais concentraram as origens dos deslocamentos diários por motivo de trabalho com as áreas de concentração de residência de pessoas hospitalizadas por síndrome respiratória grave (SRAG) - o que inclui casos de Covid-I9, mas não apenas. Ambos estavam, em sua maioria, localizados nas periferias da cidade. Com isso, os pesquisadores concluíram que "quem está sendo mais atingido pela Covid-ı9 são as pessoas que tiveram que sair para trabalhar", ou seja, pessoas que não têm condições de trabalhar de casa - um privilégio típico de quem tem nível de escolaridade mais alto, como será detalhado mais adiante - ou não podem ficar sem trabalhar, pois não contam com uma rede de proteção social que lhes possibilite manter o distanciamento social (MARINO et al., 2020).

Adicionalmente, dados apresentados por Ribeiro et al. (2O2I) sobre mortalidade por Covid-I9 entre março e setembro de 2020 , apontam que, entre os moradores de bairros paulistanos com menor percentual de pessoas com curso universitário, a taxa de mortalidade por Covid-I9 foi quatro vezes maior quando comparada com bairros em que o nível educacional é mais alto. Pretos e pardos apresentaram taxas de mortalidade 8I \% e 45\% maiores do que brancos, respectivamente. Do mesmo modo, todos os indicadores de status socioeconômico - menos educação, mais aglomeração familiar, menor renda e maior concentração de aglomerados subnormais - foram associados a maiores taxas de mortalidade. Isso se deve não só à maior taxa de contaminação de pessoas pobres, mas também à deficiência no atendimento público em saúde. Enquanto a mortalidade de pacientes com Covid-I9 internados em UTIs privadas foi de 30\%, em UTIs públicas essa taxa foi de $53 \%$ (COSTA et al., 202I).

O segundo impacto da pandemia sobre os moradores das periferias, e que tende a se agravar ao longo dos próximos meses, está no aspecto socioeconômico. A perda de trabalho ou a redução da renda atingiu em cheio as famílias mais pobres. Segundo dados da $\mathrm{PNAD}^{6}$ Covid-I9, realizada pelo IBGE, a taxa de desocupação em setembro de 2020 estava em I $4,4 \%$, o que representava mais de I4 milhões de pessoas desempregadas. Além disso, I5,3 milhões de pessoas não procuraram trabalho por conta da pandemia ou por falta de trabalho na localidade onde moram. Nesse aspecto, questões de raça e de nível de escolaridade também têm peso relevante. Enquanto 5,9\% das pessoas que se autodeclaram brancas não procuraram trabalho, esse número sobe para 9,7\% entre pretos e pardos. Entre as pessoas

\footnotetext{
${ }^{6}$ Disponível em : <https://covid19.ibge.gov.br/pnad-covid/>. Acesso em: 10 abr. 2021
} 
com ensino superior, a desistência da busca pelo emprego estava em $3,7 \%$, já entre as que concluíram apenas o nível fundamental ou médio, essa taxa era de mais de $9 \%$.

Os trabalhadores com ensino superior são também aqueles que mais se beneficiam de realizar trabalhos remotos (home office). Enquanto 27,I\% das pessoas com ensino superior completo ou pós-graduação seguiam trabalhando de suas casas, em novembro de 2020 (taxa que chegou a $38,3 \%$ no primeiro trimestre da pandemia), menos de I\% das pessoas que não haviam completado o ensino médio contavam com essa possibilidade. Entre os que haviam concluído ao menos o ensino médio, essa taxa era de $4,4 \%$ naquele momento. ${ }^{7}$

Com relação aos rendimentos, estudo da Fundação Getúlio Vargas (FGV), de setembro de 2020 , já apontava que a renda proveniente do trabalho dos brasileiros havia caído, em média, 20,I\% entre o primeiro e o segundo trimestre daquele ano. Para a metade mais pobre da população, essa queda, no entanto, foi muito mais intensa, chegando a 27,9\%; enquanto para os IO\% mais ricos, a queda havia sido de $17,5 \%$ (NERI, 2O2O).

Como já alertavam os boletins da Rede de Pesquisa Solidária de 17 e 24 de abril (BARBOSA; PRATES, 2O20b,a), um quarto da força de trabalho brasileira se enquadra no que se pode chamar de "trabalhador mais vulnerável em setor não essencial", ou seja, pessoas que trabalham por conta própria, como trabalhadores domésticos e empregados sem carteira ou de pequenas empresas em setores passíveis de paralização por medidas sanitárias de distanciamento social. A ocupação dessas vagas encontra forte correlação com a baixa escolaridade, com a raça (negros) e com o sexo (mulheres). Assim, mulheres negras e homens negros com pouco acesso ao ensino formal, que tradicionalmente são os mais vulneráveis no mercado de trabalho, encontram-se em posições ainda mais frágeis no atual momento.

É preciso lembrar que a crise econômica provocada pela pandemia chegou ao país em um momento em que o nível de desemprego, informalidade e desalento - pessoas que haviam desistido de procurar trabalho por não terem mais esperança de encontrar - já estava extremamente elevado, criando uma "tempestade perfeita" do ponto de vista econômico. Entre 2014 e 20I7, a pobreza no Brasil havia aumentado 33\%, passando de $8,3 \%$ para II, $8 \%$ o que representava um contingente adicional de 6,3 milhões de "novos pobres" (NERI, 2OI8). Além disso, enquanto em meados de 20I4, os 50\% mais pobres se apropriavam de cerca de $5,7 \%$ de toda a renda do trabalho, no primeiro trimestre de 2019 , aquela fração havia caído para 3,5\%, o que significa, em termos relativos, uma queda de quase 40\% (BARBOSA, 2019).

A partir de 2017, o setor informal, mais desigual e instável, passou a se expandir, mitigando os impactos da crise, e desacelerando e estabilizando o crescimento da taxa de

\footnotetext{
${ }^{7}$ Disponível em : <https://covid19.ibge.gov.br/pnad-covid/>. Acesso em: 10 abr. 2021.
} 
desemprego. Desse modo, no começo de 2020, o Brasil já apresentava uma taxa de desemprego de $12,6 \%$, com mais $5 \%$ de desalento. Adicionalmente, naquele momento, $40 \%$ dos trabalhadores brasileiros estavam na informalidade, estando, portanto, fora da rede de proteção social oferecida pelos direitos trabalhistas (PRATES; BARBOSA, 2020). Em 2OI9, antes, portanto, do início da pandemia no Brasil, era possível dizer que para os trabalhadores mais pobres, a recessão não havia terminado e sua renda ainda estava em queda, mesmo quando descontados os efeitos do desemprego (BARBOSA, 20I9).

Com o término do Auxílio Emergencial, no fim de 2020, a situação se agravou ainda mais. Levantamento da FGV apontou que o número de pobres no Brasil saltou de 9,5 milhões em agosto de 2020 para mais de 27 milhões em fevereiro de 202I (JORNAL NACIONAL, 2O2I), total que pode chegar a 6I,I milhões, conforme estimativa do Centro de Pesquisa em Macroeconomia das Desigualdades da Universidade de São Paulo (Made/USP). ${ }^{8}$

Nesse sentido, segundo dados de um levantamento realizado pelo Instituto Data Favela, no início de fevereiro de 202 I $68 \%$ dos moradores de favelas não tinham dinheiro para comprar comida em ao menos um dia nas duas semanas anteriores ao levantamento. $\mathrm{O}$ levantamento mostra também que o número de refeições diárias dos moradores das comunidades vem caindo: de uma média de 2,4 , em agosto de 2020, para I,9, em fevereiro de 202I (BOCCHINI, 202I). Na mesma direção, relatório publicado pela Rede Brasileira de Pesquisa em Soberania e Segurança Alimentar e Nutricional (PENSSAN, 202 I) indica que $55,2 \%$ dos brasileiros se encontravam em situação de insegurança alimentar e $9 \%$ conviviam com a fome. Isso significa que 43,4 milhões de brasileiros não tinham alimentos em quantidade suficiente para suprir suas necessidades cotidianas e I9 milhões de brasileiros enfrentavam a fome. Além disso, o relatório mostra que a insegurança alimentar grave aumentou $19 \%$ nos domicílios onde algum morador havia perdido o emprego ou houve endividamento em razão da pandemia, e que nos domicílios em que residiam pessoas que receberam o Auxílio Emergencial, a insegurança alimentar moderada ou grave é três vezes superior à média nacional observada.

Com relação a outro direito fundamental que afeta o desenvolvimento de crianças e jovens - a educação -, os mais pobres e moradores de periferias urbanas também são os que mais sentem os impactos das restrições provocadas pela pandemia: 55\% dos estudantes de favelas do Brasil estavam sem estudar durante a pandemia, conforme pesquisa realizada pelo Data Favela, em junho de 2020. Parte desses estudantes (34\%) não conseguia participar das

\footnotetext{
${ }^{8}$ Os estudos citados consideram pobres pessoas que vivem com uma renda mensal per capita inferior a R\$ 469 por mês, ou US\$1,90 por dia, conforme critério adotado pelo Banco Mundial. Já os extremamente pobres são aqueles que vivem com menos de R\$ 162 mensais (BBC NEWS, 2021).
} 
atividades oferecidas por falta de acesso à internet, e outra parcela (2I\%) não estava recebendo as atividades da escola ou da faculdade (DATA FAVELA, 2020a).

A falta de acesso à internet e a equipamentos adequados é uma das principais dificuldades enfrentadas por crianças e jovens que estão sem frequentar aulas presenciais. Pesquisa realizada um ano antes da pandemia no Brasil pelo Centro Regional de Estudos para o Desenvolvimento da Sociedade da Informação (CETIC, 2020) revelou que um quarto dos brasileiros ainda não tem acesso à internet. Entre os que têm acesso à rede, $58 \%$ o fazem somente pelo celular, percentual que chega a $85 \%$ nas classes D e E.

Diante desse quadro de desigualdade na disponibilidade aos serviços e equipamentos de telecomunicações, a Pesquisa juventudes e a pandemia do coronavírus, realizada pelo Conselho Nacional de Juventude (CONJUVE, 2020) apontou que, em média, estudantes das escolas privadas tiveram 2,3 equipamentos à disposição contra I,6 dentre estudantes das escolas públicas. Com relação especificamente ao acesso a computadores ou notebooks, apenas $29 \%$ dos estudantes da rede pública dispunham desses equipamentos em casa, contra 7I\% dos alunos da rede privada (LIMA, 2020). Com isso, 69\% dos estudantes que frequentam o ensino médio na rede pública concordam, totalmente ou em parte, que os equipamentos à sua disposição são pouco adequados para os estudos, taxa que cai para a $48 \%$ dentre os estudantes da rede privada (LIMA, 2O2O).

Muitas vezes, no entanto, o problema da falta de acesso dos jovens mais pobres à educação durante a pandemia não estava relacionado apenas à ausência de equipamentos adequados, mas ao não oferecimento de conteúdo pelas escolas. Enquanto $90 \%$ dos estudantes do ensino médio de escolas privadas afirmavam ter, em meados de 2020 , aulas em plataforma digital com mediação do professor, apenas $35 \%$ dos alunos de escolas públicas tinham acesso a esse tipo de recurso (LIMA, 2020). Com isso, 26\% dos estudantes negros do ensino médio não estavam assistindo às aulas, nem a distância, em junho de 2020, taxa que cai para $8 \%$ entre estudantes brancos (DATA FAVELA, 2020a). No mesmo sentido, o boletim 22 da Rede de Pesquisa Solidária de agosto de 2020 (PRATES; GUICHENEY, 202O) apontou que mais de 8 milhões de crianças entre 6 e i4 anos ficaram sem atividades escolares para fazer em casa, o que representa $30 \%$ dos estudantes mais pobres e menos de $4 \%$ entre os mais ricos. Com isso, a diferença de atividades realizadas em casa, entre pobres e ricos, pode chegar a 224 horas, o equivalente a 50 dias letivos. Nesse cenário, 59\% dos estudantes de ensino médio em escolas públicas diziam que a pandemia de Covid-ı havia impactado muito no aproveitamento do conteúdo escolar (DATA FAVELA, 2020a) e $84 \%$ dos pais acreditavam que o filho não estava conseguindo estudar em casa como deveria (LIMA, 2O2O). 
Além da defasagem de aprendizado entre os estudantes mais pobres, as consequências dessa situação estão também no risco de aumento da evasão escolar. Mais de um quarto dos jovens entrevistados na pesquisa da Conjuve (2020) afirmou que já pensou em não voltar para a escola ao final do período de suspensão das aulas. Mais uma vez, essa realidade é maior entre os estudantes das redes públicas (30\%), quando comparados àqueles que frequentam as escolas da rede privada (19\%). Do mesmo modo, é também maior o risco de interrupção da trajetória escolar de estudantes que se autodeclaram pretos (30\%), seguidos pelos que se identificam como pardos (27\%) e brancos (25\%)(LIMA, 2020). Além disso, $75 \%$ dos pais e das mães moradores de favelas sentiam muito medo da possibilidade de os filhos perderem o ano escolar ou repetirem o ano (DATA FAVELA, 2020a).

Por fim, mas não menos importante, é preciso chamar atenção para os efeitos psicológicos e de violação de direitos que essa situação inédita acarreta. Com a incerteza, o medo e a angústia de permanecer trancado em casa, têm sido frequentes os relatos de abuso de álcool e outras drogas. Do mesmo modo, a violência psicológica, física e sexual contra mulheres e crianças têm aumentado, com o agravante da dificuldade de realizar denúncias ou evitar o convívio cotidiano com o agressor, como já alertava o Instituto Maria da Penha, em nota divulgada em abril de 2020. ${ }^{9} \mathrm{O}$ tempo revela que essa preocupação tem se mostrado bastante pertinente. Conforme levantamento do Instituto Patrícia Galvão e do Instituto Locomotiva (2020), realizado com I.5OO pessoas, em outubro de $2020,28 \%$ dos entrevistados diziam conhecer uma mulher que sofreu agressão de atual ou ex-companheiro durante a pandemia. Para $87 \%$, a pandemia fez com que a violência contra mulheres aumentasse, apontando como principais problemas abuso de álcool, estresse, aumento da convivência, falta de dinheiro e sobrecarga da mulher por falta da divisão do trabalho em casa. Além disso, $49 \%$ acreditavam que a pandemia atuou como fator que dificultou para a mulher denunciar a violência doméstica.

O recrudescimento da pandemia e a necessidade de medidas de distanciamento social, no início de 202I, parece ter agravado ainda mais esse quadro. Dados do governo federal, apontam que no mês de março houve um aumento de 165,6\% nas denúncias de violações de direitos humanos relacionadas à pandemia de Covid-I9 por meio do canais Disque Ioo e Ligue I80. Mais uma vez, o grupo mais atingido são pessoas em situação socialmente vulnerável, representadas por $53 \%$ das denúncias sobre a crise sanitária, além de outros

\footnotetext{
${ }^{9}$ Disponível em: <https://www.institutomariadapenha.org.br/assets/downloads/nota_publica_abril_2020.pdf>. Acesso em: 23 abr. 2021.
} 
grupos, como mulheres, idosos, crianças e adolescentes, pessoas com deficiência, e pessoas em restrição de liberdade(BRASIL, 202I).

Relatório da Anistia Internacional (202I, on-line) apontou também que "nas favelas e em outras áreas marginalizadas, a violência policial intensificou-se durante a pandemia de Covid-I9". Entre janeiro e junho de 2020, pelo menos 3.I8I pessoas (79\% delas negras) foram mortas pela polícia em todo o país, o que representa uma média de 17 mortes por dia , 7, I\% a mais do que em 2019. Apenas no estado de São Paulo, os policiais mataram 514 civis entre janeiro e junho, um aumento de $20 \%$ em relação ao mesmo período de 2019 , o maior número desde que os registros começaram a ser coletados em 2001.

Esses são apenas alguns dados que apontam para as fragilidades a que estão ainda mais expostos moradores de favelas e áreas periféricas dos grandes centros urbanos. Como os dados sobre aumento da violência policial apontam, não se pode dizer que o Estado brasileiro não tenha atuado durante a pandemia, mas que se trata de uma atuação seletiva e desigual.

\section{Da objetividade à experiência: a pandemia na ótica das lideranças comunitárias}

A simples existência de um problema não o torna automaticamente um "problema público". A fome, a desigualdade social, a violação de direitos humanos, a dificuldade de acesso a serviços públicos de saúde e educação de qualidade não são propriamente problemas novos no Brasil. No entanto a pandemia de Covid-I9 agravou e escancarou essas questões, e trouxe para o centro do debate público a necessidade de medidas concretas e urgentes para mitigá-las.

Ainda assim, a publicação de artigos científicos e de notícias na imprensa não são suficientes para dar esse caráter público a uma questão. É preciso que uma "arena pública" se forme em torno dessa "situação problemática" a partir de uma "ecologia de experiências" que mobilize as pessoas para agir e reivindicar soluções. Por isso, para além da constatação dos problemas por meio de dados, números e estudos que afetam desigualmente os moradores das periferias urbanas do ponto de vista objetivo, como foi feito na seção anterior, cumpre analisar como esses sujeitos têm vivenciado essa realidade e se mobilizado para contorná-la. É por meio de uma experiência coletiva que o distúrbio pode ser problematizado e divulgado para que as pessoas saibam com o que estão lidando e o que fazer com isso (CEFAÏ, 20I7a).

Osni, homem negro de 48 anos de idade, com quem este autor mantém relação de amizade desde 2016 por ocasião da pesquisa de doutorado, tem sua história ligada às Comunidades Eclesiais de Base que funcionavam na região do Jardim Ângela, periferia sul de São Paulo e às pastorais da juventude e do negro. Atualmente, é coordenador do Centro São José, no Jardim Ângela, um centro comunitário ligado à Sociedade Santos Mártires e que 
oferece serviços de assistência social para crianças e adolescentes em convênio com a prefeitura de São Paulo. ${ }^{10}$

Em julho de 2020, em conversa telefônica com Osni, ele disse que, por estar em um centro comunitário e ter longa experiência de relação e mobilização com a comunidade e a operação de serviços públicos, estava em uma posição privilegiada de observação da realidade periférica. Osni contou que nos dois primeiros meses de pandemia, a principal questão que recebeu foi com relação a informações sobre como acessar os programas de governo, principalmente o Auxílio Emergencial. A partir do fim de abril, no entanto, segundo ele, “começou a busca por alimentação", ou seja, pela doação de cestas básicas.

Nesse aspecto, Osni relatou algo peculiar. Naquele momento em que o Auxílio Emergencial de R $\$ 600$ estava sendo pago aos mais pobres e à parte dos trabalhadores informais, ele disse que a necessidade de alimentos estava afetando "pessoas que a gente jamais pensou que precisaria de cesta [básica] [...] aquela classe $C$, que estava bem financeiramente, estava equilibrada, essa tem sofrido bastante a consequência da questão da alimentação".

Uma terceira ordem de problemas que Osni relata está relacionada à violência. No centro comunitário que ele coordena, foi realizado um processo de monitoramento com 300 famílias da região, no qual "foi muito relatada a questão da violência psicológica". Em sua leitura, "o confinamento agravou muito essa questão, claro, [a violência] sexual, física também, mas aumentou muito violência psicológica".

Osni reforçou a percepção a respeito da dificuldade das famílias das periferias urbanas em acessar a internet e proporcionar a crianças e jovens o acesso a conteúdos educacionais durante o período de fechamento das escolas.

Outra coisa que é muito relatada é a dificuldade de acesso à internet. Uma coisa impressionante. Nós já tínhamos ajudado as famílias a entender o pedido do governo do estado e do município do acesso às aulas on-line, e ali nós já começamos a perceber que as famílias estavam sofrendo porque vários não tinham esse acesso. Algo que pra nós teria mais de 50\% [das pessoas com acesso], tranquilo, estourando, muito mais. E quando nós começa mos a falar com as famílias e perguntar como estava o acesso pra que a gente pudesse fazer o monitoramento e fazer atividades com as famílias, descobrimos que uma boa parte não tem acesso. Pensando em crianças, adolescentes e jovens, vários utilizam o celular do pai e da mãe ou dos responsáveis, e mesmo assim com um limite muito grande de dados, tem ali

\footnotetext{
${ }^{10}$ Para mais informações sobre a história da Sociedade Santos Mártires e sua importância na região do Jardim Ângela, ver Fontes (2018a, b, 2020).
} 
um crédito muito pequeno. Então o pai e a mãe ficam restringindo, ou eles também ficam sem internet. Isso é algo que nos preocupou muito, pois como ter aula on-line se não tem internet? Nós achávamos que a maioria dos jovens teria celular, mas a maioria não tem o aparelho. E isso agravou muito, né? Porque, na crise, se o pai e a mãe têm que ter prioridades, não vão comprar um aparelho celular. Essa questão da internet é um ponto importante para ser avaliado. ${ }^{11}$

A fala de Osni resume bem a situação dos moradores de periferias urbanas constatada pelos dados expostos anteriormente e também pelo Painel de Monitoramento de Lideranças Comunitárias da Rede de Pesquisa Solidária. Entre maio e agosto de 2020, o painel formado por diversos pesquisadores do Brasil ${ }^{12}$ entrevistou mensalmente, por meio de aplicativos de troca de mensagens de celular, algumas dezenas de lideranças comunitárias das regiões metropolitanas de Manaus, Recife, Belo Horizonte, Rio de Janeiro, São Paulo, Distrito Federal, Campinas, Salvador, Joinville e Maringá em quatro rodadas mensais de pesquisa. Foram realizados entre 130 e 150 contatos a cada rodada, e as respostas obtidas variaram entre 60 e 80 a depender do mês.

Uma mesma pergunta se repetiu em todas as rodadas, buscando compreender quais os principais problemas vividos pelas comunidades naquele momento da pandemia. Os dados estão compilados no Gráfico I. Questões como segurança alimentar e outros temas ligados a trabalho, emprego e renda foram, ao longo de toda a pesquisa, os mais citados. Ainda assim, é importante notar que as menções a esses temas diminuíram ao longo do tempo, provavelmente como efeito do Auxílio Emergencial pago naquele momento. De outro lado, aumentaram consideravelmente as preocupações com falta de acesso a outras políticas públicas, como educação e justiça, que tiveram um crescimento de I0\% nas duas primeiras ondas para mais de 30\% na quarta onda. Do mesmo modo, a preocupação com o contágio pela Covid-I9 nas periferias, que havia sido mencionada por apenas $6 \%$ no mês de maio, cresceu cinco vezes no mês seguinte e se manteve em patamar elevado, com mais de $26 \%$ de citações, o que aponta para o crescimento e a manutenção das taxas de contaminação elevadas entre moradores das periferias urbanas.

\footnotetext{
11 Informação verbal, julho de 2020.

${ }^{12}$ Esse painel da rede foi coordenado por Graziela Castello (CEBRAP), Priscila Vieira (CEBRAP) e Monise Picanço (CEBRAP), e contou com a colaboração de Dafny Almeida (CEBRAP), Daniela Costanzo (CEBRAP), Jaciane Milanezi (CEBRAP), Jonatas Mendonça dos Santos (USP), Laura Simões (USP), Leonardo Fontes (CEBRAP) e Rodrigo Brandão (USP).
} 


\section{Gráfico 1. Principais problemas vividos pela comunidade durante a pandemia - respostas múltiplas - principais recorrências \%.}

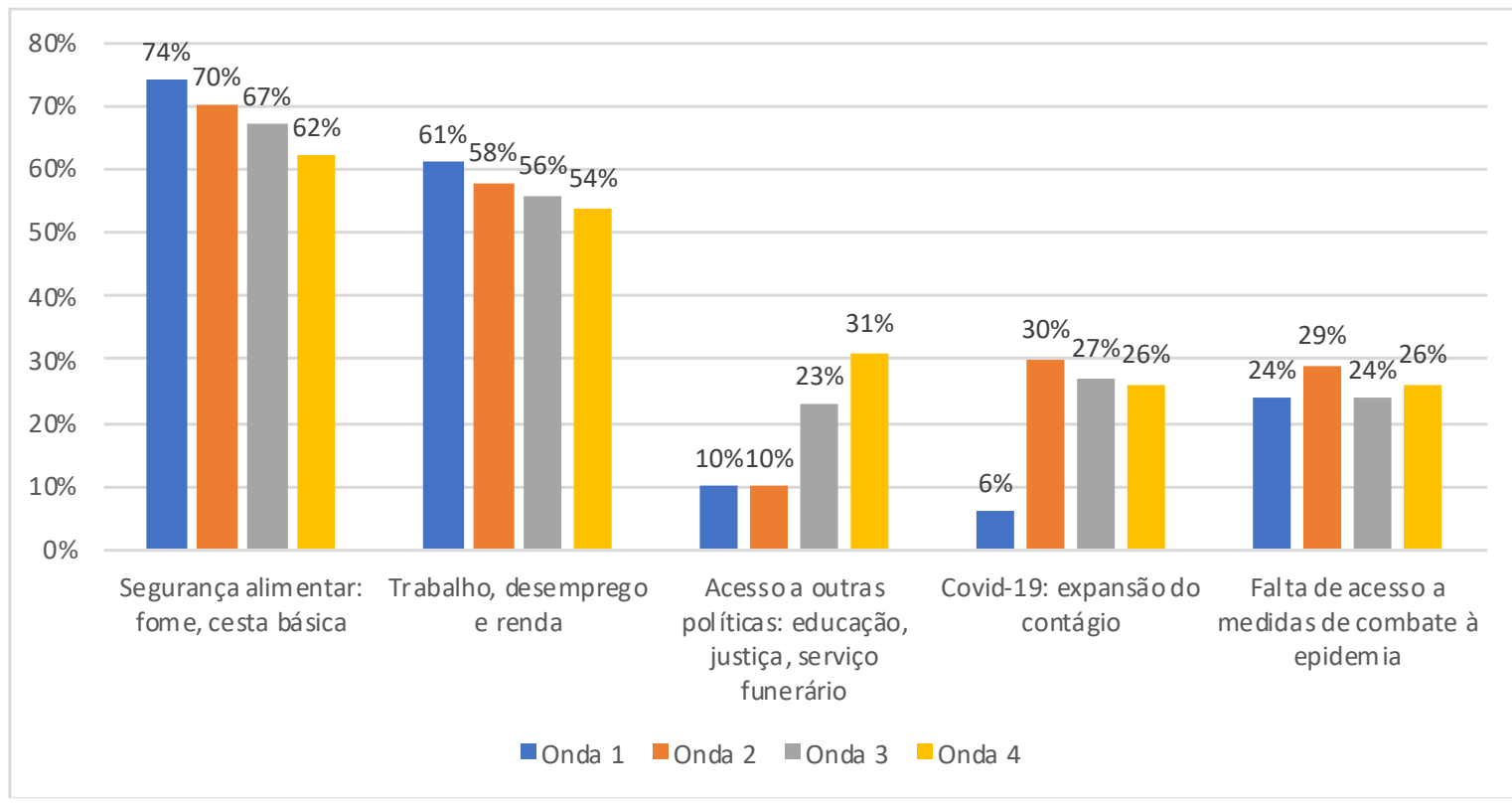

Fonte: Castello et al. (2020). Onda $1=5$ a 11 de maio, $N=72$; Onda $2=25$ de maio a 6 de junho, $N=79$; Onda $3=6$ a 16 de julho, $N=75 ;$ Onda $4=17$ a 30 de agosto, $\mathrm{N}=64$.

$\mathrm{N}=$ Número de respondentes naquela rodada de pesquisa.

Dados objetivos transformam-se em percepções subjetivas, e com isso, em experiências coletivas, quando foram analisados os depoimentos de Osni e das demais lideranças comunitárias entrevistadas pela equipe da Rede de Pesquisa Solidária. Na vida cotidiana dessas localidades, não existe uma dicotomia entre saúde e economia ou entre restrições sanitárias e liberdades individuas, como os discursos de Bolsonaro tentam dar a entender. Tratam-se de faces de uma mesma crise que se sobrepõem à penúria econômica não superada desde 2015 e aos problemas de educação, assistência social e violação de direitos fundamentais sempre presentes e agora intensificados.

\section{"Nós por nós": construção de arenas públicas e fortalecimento da solidariedade periférica}

Seguindo a linha do entendimento teórico aqui proposto, pode-se afirmar que:

[...] uma mobilização coletiva emerge quando os membros de uma coletividade (ainda indeterminada, e cujos contornos, tamanho e composição serão especificados durante o processo), sentindo-se concernidos, direta ou indiretamente, por um "distúrbio" com que são confrontados (primeiro de modo indistinto, difícil de captar e designar, ainda não admissível por um público), definem-no como uma situação 
problemática e resolvem passar à ação (de modo indissociavelmente conjunto e conflituoso, envolvendo-se em cooperações e competições de todo tipo) para resolvê-lo. (CEFAÏ, 20I7a, p. 189)

No último ano, mesmo distante fisicamente das regiões onde realizo pesquisa na periferia de São Paulo, notei, a partir de relatos, pedidos de doação e depoimentos dos interlocutores dessas regiões com quem mantenho contato por meio de redes sociais, que inúmeras iniciativas de cooperação, solidariedade e ajuda mútua têm surgido desde o começo da pandemia. Não é o caso de catalogar essas iniciativas, algo que seria impossível do ponto de vista prático. O objetivo aqui é apenas registrar que elas existem e atuam em duas frentes paralelas: arrecadação e distribuição de alimentos, kits de higiene, máscaras, entre outros itens; e a reivindicação de políticas públicas efetivas, sobretudo o auxílio emergencial e a melhoria de serviços públicos, como saúde e educação.

Apenas para ficar em alguns exemplos acompanhados mais de perto, a Sociedade Santos Mártires, onde Osni atua há mais de 25 anos, distribuiu cerca de 23.500 cestas básicas, I4.500 kits de higiene e limpeza, Ioo mil máscaras, 70 mil kits de sabonetes e 40 mil frascos de álcool em gel. Na Brasilândia, outra região de pesquisa, a campanha Brasilândia Nossas Vidas Importam, do coletivo Brasilândia: na Luta, arrecadou até o momento de escrita deste texto I. 216 cestas básicas, 270 kits de higiene, I.230 máscaras de pano, I tonelada de alimentos e 3.402 preservativos.

Além da arrecadação e distribuição de alimentos, entidades que atuam em outras áreas têm buscado suprir algumas das demandas identificadas anteriormente, como é o caso de cursos populares, que têm procurado organizar a doação e a distribuição de chips de celulares para que alunos das periferias possam acessar o conteúdo e as aulas on-line - como a campanha $4 \mathrm{G}$ para Estudar $-{ }^{13}$, e iniciativas de mapeamento e denúncia de violação de direitos humanos - como o projeto Salve Sul: Observatório dos Direitos Humanos, do Centro de Direitos Humanos e Educação Popular (CDHEP/Campo Limpo), que tem como missão identificar e mapear violações em tempos de Covid-19. ${ }^{14} \mathrm{Na}$ área de geração de trabalho e renda, pude acompanhar e apoiar neste último ano a criação da Rede Sul - Quebrada Presente, formada por proprietários de pequenos negócios - sobretudo mulheres - da

\footnotetext{
13 Mais informações em: <https://www.4gparaestudar.org.br/>.

14 Mais detalhes em: <http://cdhep.org.br/mapa-salvesul/>.
} 
periferia sul de São Paulo, a fim de construir ações de apoio entre os empreendedores, como cursos de formação e catálogos coletivos de produtos e serviços, e reivindicar políticas públicas para o setor..$^{15}$

Segundo dados do Data Favela (2020b), nove em cada dez moradores de favelas receberam alguma doação durante a pandemia, 69\% dessas doações tiveram como origem ONGs ou empresas, e 52\%, vizinhos ou parentes. Além disso, de acordo com a mesma pesquisa, enquanto $49 \%$ dos brasileiros afirmam ter realizado algum tipo de doação durante a pandemia, entre os moradores de favelas, esse número sobe para $63 \%$.

A importância dessas iniciativas é inequívoca, mas a hipótese aqui defendida é que essa importância vai muito além do atendimento de uma necessidade urgente de maneira assistencial. Na última pesquisa de 2020 da Rede de Pesquisa Solidária, realizada em agosto, foi perguntado às lideranças comunitárias quais efeitos futuros a pandemia poderia ocasionar em suas comunidades. Além de trazer mais uma vez à tona os problemas já apontados ao longo deste texto, como impactos no mercado de trabalho e perda de renda, $38,7 \%$ dos respondentes acreditam que a pandemia poderá trazer mais solidariedade e ampliar o senso de comunidade em suas regiões, como aponta o Gráfico 2.

\section{Gráfico 2. Efeitos esperados da pandemia no futuro das comunidades.}

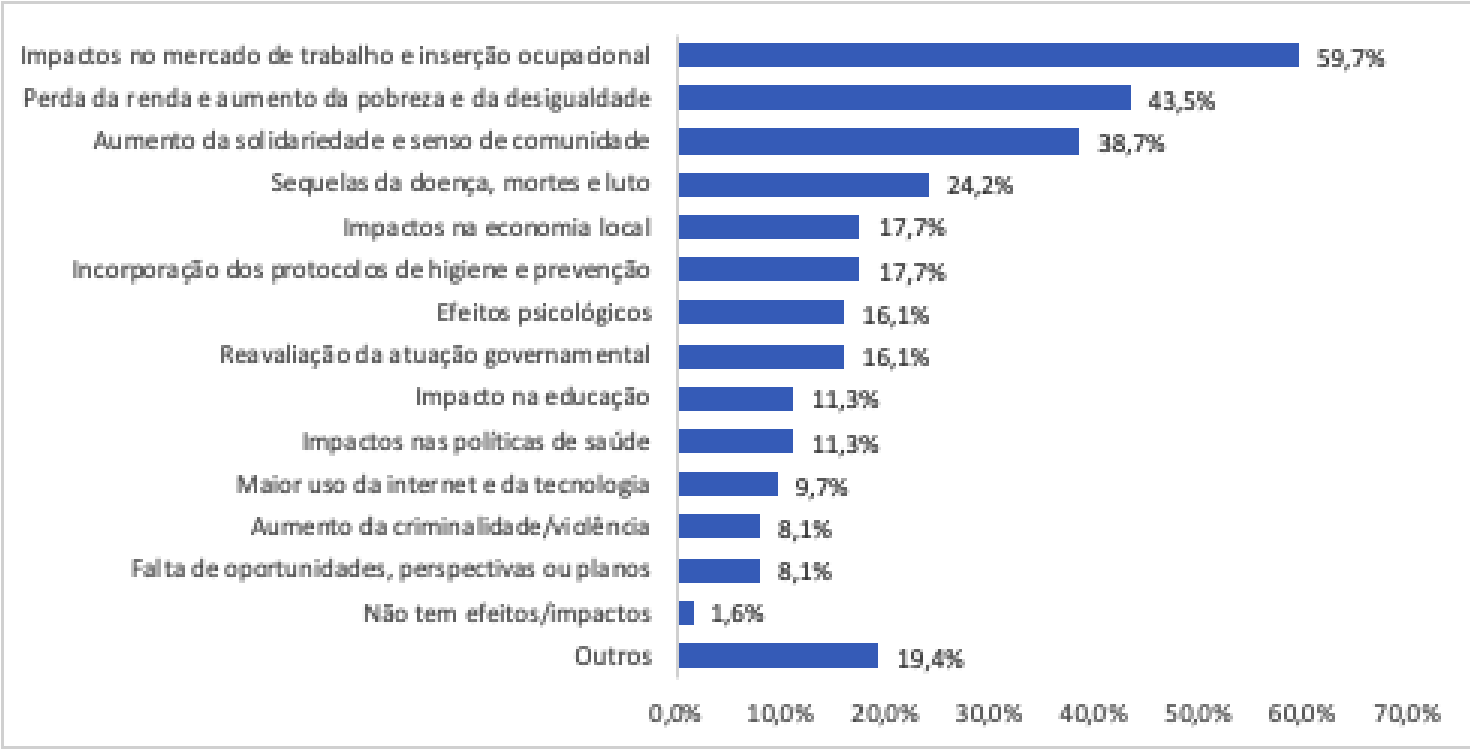

Fonte: Castello et al. (2020). N = 62. Respostas múltiplas (\%).

\footnotetext{
${ }^{15}$ Ainda que se trate de um levantamento parcial, a equipe do LabCidade apontou, em 6 de março de 2021, 33 campanhas de doação; 36 cartas, manifestos, campanhas e articulações com propostas e medidas emergenciais; mais de 20 dispositivos e materiais informativos produzidos por coletivos; e 22 plataformas de mapeamento de iniciativas, casos de contaminação e denúncias.
} 
Os depoimentos coletados pela Rede de Pesquisa Solidária ajudam a ir além da simples constatação de que essas redes e iniciativas de apoio e solidariedade foram muitas e fundamentais para evitar que os efeitos da pandemia sobre os mais pobres fossem ainda mais devastadores, mas também para fortalecer os laços e a mobilização coletiva dessas regiões. Peço licença para as longas citações, mas acredito que elas falam por si mesmas.

Um ponto positivo que deixou para as favelas do Rio de Janeiro e de todo o Brasil é que nas favelas do Rio de Janeiro existem pessoas que têm nível superior e que se uniram, sentaram à mesa, não como políticos, mas como líderes comunitários nascidos e criados e que sabem a rotina da comunidade, que sabem como a comunidade funciona. Sentaram, se reuniram, discutiram políticas públicas comunitárias para serem implementadas durante a pandemia, para que a gente pudesse evitar um pico de casos nas favelas. Então nós montamos uma rede de solidariedade, uma cadeia de suprimentos muito grande para poder abastecer as pessoas que estavam no isolamento social, faziam parte do grupo de risco e receberam doações de cestas básicas e kits de limpeza. A cobertura foi total nesse sentido. Eu posso dizer que as comunidades estão preparadas para qualquer pandemia que vier afetar as favelas. (Líder comunitário do Morro da Coroa, Rio de Janeiro)

O "nós por nós" funcionou bem neste período de pandemia. Tem muita rede de apoio se fortalecendo, fortalecendo as pessoas. Organizações e coletivos buscando representar suas comunidades. Muita solidariedade, empatia. Acredito que esses são os pontos fortes, é o que pode fazer nascer frutos no futuro. Nosso povo compreendendo que é necessário lutar coletivamente contra o sistema. Se as periferias já tinham fome, miséria e violência, teremos muito mais a partir de agora; a pandemia só agravou as desigualdades sociais. Para os próximos capítulos, esperançamos que haja investimento em proteção social. (Líder comunitária do Jardim São Luís, São Paulo)

Percebo que teve também um movimento maior com a comunidade. Então eu acho que esse espírito de solidariedade também se intensificou. Talvez ter um cuidado de não perder a dimensão de garantia de direitos e ficar somente como um assistencialismo. Mas eu acho que, entre as pessoas, entre os moradores, também se ampliou uma discussão de cuidado, de solidariedade entre a vizinhança.(Líder comunitário de Sapopemba, São Paulo).

A gente está tentando ajudar várias demandas aqui, mas não tem o financeiro ou o poder público fortalecendo no que a gente vem vivenciando. 
Quem vem nos ajudando aqui no nosso território são os coletivos que agregam e acreditam no que a gente vem vivenciando aqui na realidade. Com a crise, a gente fez várias entregas aqui. Entrega de cesta básica, cartão das mães das favelas; a gente teve projeto da Cufa, teve projetos sociais de outras ONGs que chegaram entregando máscara, álcool em gel, tudo isso. [...] Então isso vai ficar como um exemplo também até para a gente aqui do território. A comunidade viu isso na prática, né? [...] E aí eu acredito sim numa evolução, que a gente passou por um processo delicado de sobrevivência, e aquelas pessoas que sobreviveram vão ter um fortalecimento maior lá na frente por conta dessa pandemia e também por conta da força de vontade mesmo, e das pessoas que foram sensíveis a tudo isso, porque se não fossem as comunidades umas ajudando as outras, pode ter certeza que os territórios do Brasil todo estavam passando fome, porque o poder público em vários territórios virou as costas, cruzou os braços e deu uma de doido. (Líder comunitário de Iburra, Recife)

A ideia de "nós por nós", citada pela líder comunitária do Jardim São Luís, pode parecer associada a uma rejeição de apoios externos. Na verdade, esse termo tem representado nos discursos de artistas periféricos, membros de coletivos culturais e outras lideranças periféricas um orgulho da capacidade de resistência e fortalecimento mútuo entre iguais, mas sem "perder a dimensão de garantia de direitos" como aponta o líder de Sapopemba (FONTES, 2020a, b). Nesse aspecto, cumpre ressaltar os manifestos e abaixo-assinados que têm sido promovidos por coletivos e movimentos sociais das periferias, reivindicando, por exemplo, ampliação de leitos de UTI nas cidades, distribuição de máscaras e álcool em gel à população, retorno do Auxílio Emergencial de $\mathrm{R} \$ 600$, crédito aos comerciantes, estabilidade nos empregos, entre outros.

Essa mobilização periférica tem como consequência, portanto, a formação de "arenas públicas", que são espaços sociais "cujos atores visam bens públicos, referem-se ao interesse público, definem seus problemas como públicos e sentem, agem e falam em consequência disso" (CEFAÏ, 20I7a, p. 200). Ao tomarem consciência de que diante da situação problemática provocada ou acelerada pela pandemia de Covid-I9 seriam necessárias soluções comuns, essas pessoas se envolveram em ações coletivas "que visam uma reorganização coletiva dos equipamentos ou dos recursos disponíveis, com consequências ora radicais, ora limitadas, em suas próprias histórias de vida" (p. 206). 
Considerações finais - para além do utilitarismo: cultura pública, ação coletiva e outro paradigma de sociabilidade

O desafio posto por este artigo foi o de "descrever a mutação das experiências coletivas e dos meios institucionais, fazendo-os emergir das atividades enquanto estas se realizam", saindo de uma visão de simples exterioridade em relação ao que descreve para acompanhar as experiências e "perspectivas" dos atores (CEFAÏ, 2009, p. I5). Procurei argumentar, seguindo a sociologia pragmatista voltada para os problemas públicos, que a pandemia de Covid-I9 nas periferias urbanas foi vivenciada como uma situação problemática que obrigou os sujeitos e reorientarem suas práticas e ações no sentido de constituírem arenas públicas e transformar questões vividas em seus territórios em problemas públicos.

Esses espaços de cooperação, ajuda mútua e solidariedade são também meios de sociabilidade, nos quais emergem ocasiões de encontro que moldam as formas de coexistência e constituem conjunturas prático-sensíveis, que fixam hábitos de cooperação e de conflito e que fornecem parâmetros de experiência cognitiva e normativa, e podem funcionar como "incubadoras de redes de ativistas, chocadeira de empreendimentos de militância, geradores de energia simbólica, instâncias de representação coletiva" (CEFAÏ, 2009, p. I8-19). Nesses espaços, é possível que venha a se formar uma "cultura pública" que aponte para "novos horizontes da vida coletiva".

Trata-se obviamente de uma hipótese e uma aposta no futuro embasada na teoria social e na história de mobilização política das próprias regiões. ${ }^{16}$ Há, no entanto, outro elemento fundamental a ser considerado. Conforme aponta o líder de Sapopemba, o "espírito de solidariedade" que teria se intensificado nesse período permitiria, segundo a líder comunitária do Jardim São Luís, a ampliação da capacidade de "esperançar" - termo apropriado de Paulo Freire.

Esse espírito se relaciona diretamente à lógica de dar, receber e retribuir, tal como descrita por Marcel Mauss (2013), e que tem como essência a prevalência hierárquica do antiutilitário sobre o útil, pois mais do que produzir bens, o que importa nessa dinâmica é produzir o laço social (CAILLÉ, 2002). Na situação crítica trazida pela pandemia, e diante da resposta puramente utilitarista engendrada pelo governo federal, a mobilização e a organização coletiva de moradores de periferias urbanas apontam que se há questões relacionadas ao cálculo e ao interesse na ação social, certamente há também "obrigação, espontaneidade, amizade e solidariedade" em uma palavra: dádiva (CAILLÉ, 2002, p. I5).

\footnotetext{
16 Sobre a história de mobilização política nas periferias de São Paulo, ver Sader (1988); Feltran (2005, 2011); Fontes (2018a, b, 2020a, b).
} 
Mauss (20I3) apontou que, por meio da troca de dádivas - ou seja, por meio da troca de bens que não têm um valor unitário, mas simbólico -, os seres humanos se ligam e se constituem como sociedade. No entanto é possível ir além da mera formação de um vínculo e pensar que, nas ações de solidariedade e ajuda mútua desenvolvidas entre moradores de periferias urbanas, os sujeitos envolvido no ato de dar, receber e retribuir estão agindo segundo uma "gramática da dádiva" que pode vir a "constituir um consenso moral" em torno de valores que vão além do interesse imediato no objeto trocado. A dádiva, entendida como a simbolização da crença compartilhada em princípios morais, nos permite, então, pensar em formas de associação baseadas no livre investimento dos indivíduos em redes de obrigações, que não são redutíveis ao interesse individual nem à obrigação imposta pelo Estado (CASTRO, 2009).

Em tempo de distanciamento social e ameaça de autoritarismo político, a tarefa política está justamente na dialetização e na superação dos princípios utilitaristas advogados pelo atual governo e pelo discurso do "empreendedorismo monetarista", algo para o qual as dinâmicas periféricas aqui descritas parecem apontar.

\section{Referências}

ALONSO, A. Moto do presidente tem sido pôr abaixo tudo que o Estado brasileiro erigiu. Folha de S. Paulo, São Paulo, I7 dez. 2020. Disponível em:

$<$ https://wwwi.folha.uol.com.br/colunas/angela-alonso/2020/ı2/moto-do-presidente-temsido-por-abaixo-tudo-que-o-estado-brasileiro-erigiu.shtml $>$. Acesso em: I8 dez. 2020.

ANISTIA INTERNACIONAL. Informe 2O2O/2I: o estado de direitos humanos no mundo.

Londres, Reino Unido: Amnesty International, 2021. Disponível em:

$<$ https://www.amnesty.org/download/Documents/POLIO32O2202IBRAZILIAN\%2OPORT UGUESE.PDF >. Acesso em: 9 abr. 202I.

BARBOSA, R. Estagnação desigual: desemprego, desalento, informalidade e a distribuição da renda do trabalho no período recente (2012-2019). Mercado de Trabalho, v. 67, out. 2019.

BARBOSA, R. J.; PRATES, I. A vulnerabilidade dos trabalhadores brasileiros na pandemia da Covid-I9. Rede de Políticas Públicas \& Sociedade, Boletim 2, I7 abr. 2020b. Disponível em: $<$ https://redepesquisasolidaria.org/boletins/boletim-2/a-vulnerabilidade-dostrabalhadores-brasileiros-na-pandemia-da-covid-I9/>. Acesso em: 06 abr. 202 I. 
BARBOSA, R. J.; PRATES, I. Na crise, homens negros e mulheres negras são os mais vulneráveis. Mas surgem "novos vulneráveis", homens brancos e mulheres brancas em serviços não essenciais. Rede de Políticas Públicas \& Sociedade, Boletim 3, 24 abr. 2020. Disponível em: $<$ https://redepesquisasolidaria.org/nao-categorizado/na-crise-homensnegros-e-mulheres-negras-sao-os-mais-vulneraveis-mas-surgem-novos-vulneraveishomens-brancos-e-mulheres-brancas-em-servicos-nao-essenciais/>. Acesso em: 06 abr. $2 \mathrm{O} 2 \mathrm{I}$.

BBC NEWS. Auxílio Emergencial: com benefício reduzido em 202I, Brasil terá 6I milhões na pobreza. GI, 22 abr. 202I. Disponível em: $<$ https://gI.globo.com/economia/noticia/2O2I/O4/22/auxilio-emergencial-com-beneficioreduzido-em-202I-brasil-tera-6I-milhoes-na-pobreza.ghtml >. Acesso em: 23 abr. 2O2I.

BOCCHINI, B. Quase 70\% dos moradores de favelas não têm dinheiro para comida. Agência Brasil, São Paulo, I3 mar. 202I. Disponível em: <https://agenciabrasil.ebc.com.br/direitoshumanos/noticia/2O2I-03/quase-70-dos-moradores-de-favelas-nao-tem-dinheiro-paracomida >. Acesso em: I3 abr. 2O2I.

BOLTANSKI, L. On critique: a sociology of emancipation. New Jersey: Wiley, 2OII.

BOLTANSKI, L. Sociologia crítica e sociologia da crítica. In: VANDENBERGHE, F.; VÉRAN, J.-F. (Eds.). Além do habitus. Teoria social pós-bourdieusiana. Rio de Janeiro: 7 Letras, 2016.

BOLTANSKI, L.; THÉVENOT, L. The sociology of critical capacity. European Journal of Social Theory, v. 2, n. 3, p. 359-377, 1999.

BRASIL. Ministério da Mulher, da Família e dos Direitos Humanos. Março tem aumento de I65\% em denúncias de violação a direitos relacionadas à pandemia. Brasília: 29 mar. 202I. Disponível em: $<$ https://www.gov.br/mdh/pt-br/assuntos/noticias/2O2I/marco/marco-tem-aumento-deI65-em-denuncias-de-violacao-a-direitos-relacionadas-a-pandemia $>$. Acesso em: 23 abr. $2 \mathrm{O} 2 \mathrm{I}$.

CAILLÉ, A. Antropologia do dom: o terceiro paradigma. Tradução Ephraim Ferreira Alves. Petrópolis, RJ: Vozes, 2002.

CAMPANHAS e ações dos territórios. LabCidade, II maio 202I. Disponível em: $<$ http://www.labcidade.fau.usp.br/campanhas-e-acoes-dos-territorios/>. Acesso em: 22 maio 2O2I. 
CASTELLO, G. et al. (Coords.). Entre as lideranças, é forte a percepção de que os idosos são os mais afetados pela pandemia. A presença da fome, de crianças sem aula e pais preocupados com a falta de estrutura nas escolas acentuaram a tragédia dos mais vulneráveis. Como contraponto, há esperança de que o senso de solidariedade despertado nas comunidades seja duradouro. Rede de Políticas Públicas \& Sociedade, Boletim 24, I8 set. 2020b. Disponível em: $<$ https://redepesquisasolidaria.org/boletins/boletim-24/entre-as-liderancas-e-forte-apercepcao-de-que-os-idosos-sao-os-mais-afetados-pela-pandemia-a-presenca-da-fomede-criancas-sem-aula-e-pais-preocupados-com-a-falta-de-estrutura-nas-escolasacentuara/>. Acesso em: I2 abr. 202I.

CASTRO, R. de. A crítica e a dádiva na construção do vínculo social. Rio de Janeiro: Programa de Pósgraduação em Sociologia e Antropologia (PPGSA)/IFCS/UFRJ, 2009. Manuscrito não publicado.

CEFAÏ, D. Como nos mobilizamos? A contribuição de uma abordagem pragmatista para a sociologia da ação coletiva. Dilemas: Revista de Estudos de Conflito e Controle Social, v. 2, n. 4, p. II48, jun. 2009.

CEFAÏ, D. Públicos, problemas públicos, arenas públicas... O que nos ensina o pragmatismo (Parte I). Novos Estudos Cebrap, v. 36, n. OI, p. 187-213, 2017 a.

CEFAÏ, D. Públicos, problemas públicos, arenas públicas... O que nos ensina o pragmatismo (Parte 2). Novos Estudos Cebrap, v. 36, n. O2, p. 129-I42, $2017 \mathrm{~b}$.

CETIC - Centro Regional de Estudos para o Desenvolvimento da Sociedade da Informação. Núcleo de Informação e Coordenação do Ponto BR. Comitê Gestor da Internet no Brasil. TIC Domicilios. Pesquisa sobre o uso das Tecnologias de Informação e Comunicação nos domicílios brasileiros 2019. São Paulo, 2020. Disponível em: $<$ https://cetic.br/media/docs/publicacoes/2/2020II231218I7/tic_dom_20I9_livro_eletronico .pdf $>$. Acesso em: 9 abr. 202 I.

CONJUVE - Conselho Nacional de Juventude. Pesquisa juventudes e a pandemia do coronavírus. Brasília, 2020. Disponível em: <https://4faIdrbc-0675-4684-8ee9o3Idb9beoaab.filesusr.com/ugd/fod6I8_4Ib20Idbab994b44booaabca4If 97Ibb.pdf $>$. Acesso em: 8 abr. 2020.

COSTA, J. G. F. et al. A roleta-russa da Covid no Brasil. Piauí, o5 abr. 2021. Disponível em: $<$ https://piaui.folha.uol.com.br/roleta-russa-da-covid-no-brasil/>. Acesso em: I 2 abr. $202 \mathrm{I}$.

DARDOT, P.; LAVAL, C. A nova razão do mundo: ensaio sobre a sociedade neoliberal. São Paulo: Boitempo, 2016. 
DATA FAVELA. Educação, cultura, periferia e racismo: um levantamento do Instituto Locomotiva para a Central Única das Favelas. Cufa; Instituto Locomotiva, jun. 2020a. Disponível em: $<$ https://oca2d2b9-e33b-402b-b21759Id5I4593c7.filesusr.com/ugd/eaab2I_I6bbc9f599cd4I8ebi 2ecce3060c93a9.pdf $>$. Acesso em: 8 abr. 2O2I.

DATA FAVELA. Pandemia na favela: a realidade de I4 milhões de favelados no combate ao novo coronavírus. Cufa; Instituto Locomotiva, jun. 2020b. Disponível em: $<$ https://oca2d2b9e33b-402b-b21759Id5I4593c7.filesusr.com/ugd/eaab2I_9837d3I2494442ceae8cIIa75Ie2ao6a.pdf $>$. Acesso em: 8 abr. 202I.

FELTRAN, G. Desvelar a política na periferia: histórias de movimentos sociais em São Paulo. São Paulo: Associação Editorial Humanitas; FAPESP, 2005.

FELTRAN, G. Formas elementares da vida política: sobre o movimento totalitário no Brasil (2013-). Novos Estudos Cebrap, Blog, 2020. Disponível em: $<$ http://novosestudos.com.br/formas-elementares-da-vida-politica-sobre-o-movimentototalitario-no-brasil-2013/>. Acesso em: 20 abr. 202I.

FELTRAN, G. Fronteiras de tensão: política e violência nas periferias de São Paulo. São Paulo: Unesp, $201 \mathrm{I}$.

FONTES, L. Beyond the Institutional Order: Culture and the Formation of New Political Subjects in the Peripheries of São Paulo. Latin American Perspectives, v. 47, n. 5, p. 79-93. 2020 .

FONTES, L. de O. Da formação cultural à mobilização social: espaços de formação e mobilização ao longo de três gerações nas periferias de São Paulo. Lua Nova: Revista de Cultura e Política, n. IO9, p. 5I-IOI, $2020 b$.

FONTES, L. Do direito à cidade ao direito à periferia: transformações na luta pela cidadania nas margens da cidade. Plural: Revista de Ciências Sociais, v. 25, n. 2, 20I8a.

FONTES, L. Odireito à periferia: experiências de mobilidade social e luta por cidadania entre trabalhadores periféricos de São Paulo. Tese (Doutorado) - Instituto de Estudo Sociais de Políticos, Universidade do Estado do Rio de Janeiro, Rio de Janeiro, 20I8b.

FOUCAULT, M. Nascimento da biopolítica: curso dado no Collège de France (1977-1978). São Paulo: Martins Fontes, 2008.

GODBOUT, J.; CAILLÉ, A. O espírito da dádiva. Rio de Janeiro: Editora FGV, 1999. 
INSTITUTO PATRÍCIA GALVÃO. INSTITUTO LOCOMOTIVA. Violência doméstica contra a mulher na pandemia. Out. 2020. Disponível em: $<$ https://oca2d2b9-e33b-402b-b2I759Id5I4593c7.filesusr.com/ugd/eaab2I_d4c8ae55Ifc74c8ca5I8f8a240862ceI.pdf $>$. Acesso em: 8 abr. 202I.

JORNAL NACIONAL. Número de brasileiros que vivem na pobreza quase triplicou em seis meses, diz FGV. GI, 05 abr. 202I. Disponível em: <https://gi.globo.com/jornalnacional/noticia/202I/04/o5/numero-de-brasileiros-que-vivem-na-pobreza-quasetriplicou-em-seis-meses-diz-fgv.ghtml $>$. Acesso em: I3 abr. 2021.

LIMA, A. L. D'Í. Retratos da educação no contexto do coronavírus: um olhar sobre múltiplas desigualdades. São Paulo: Movimento de Inovação na Educação, ago. 2020.

LYNCH, C. Bolsonaro expõe autoritarismo entre neoliberais e nova "jornada de otários" liberais. Folha de S. Paulo, São Paulo, 20 mar. 2O2I. Caderno: Ilustríssima. Disponível em: $<$ https://wwwI.folha.uol.com.br/ilustrissima/2O2I/o3/bolsonaro-expoe-autoritarismo-deneoliberais-e-nova-jornada-de-otarios-de-liberais.shtml >. Acesso em: 20 abr. 202I.

MACHADO DA SILVA, L. A. Da informalidade à empregabilidade (reorganizando a dominação no mundo do trabalho). Cadernos CRH, v. I5, n. 37, p. 8I-IO9, 2002.

MARINO, A. et al. Circulação para trabalho explica concentração de casos de Covid-I9. Uol, 30 jun. 2020, A Cidade é Nossa. Disponível em: $<$ https://raquelrolnik.blogosfera.uol.com.br/2020/06/30/circulacao-para-trabalho-explicaconcentracao-de-casos-de-covid-I9/>. Acesso em: I3 abr. 202 I.

MAUSS, M. Ensaio sobre a dádiva: forma e razão da troca nas sociedades arcaicas. São Paulo: Cosac Naify, 20I3.

NERI, M.(Coord.). Efeitos da pandemia sobre o mercado de trabalho brasileiro: desigualdades, ingredientes trabalhistas e o papel da jornada. FGV Social, Rio de Janeiro, set. 2020.

Disponível em: $<$ https://www.cps.fgv.br/cps/bd/docs/Covid\&Trabalho-Marcelo_NeriFGV_Social.pdf $>$. Acesso em: 7 abr. 202I.

NERI, M. Qual foi o impacto da crise sobre a pobreza e a distribuição de renda? FGVSocial, set. 2018.

PENSSAN - Rede Brasileira de Pesquisa em Soberania e Segurança Alimentar e Nutricional. Inquérito Nacional sobre Insegurança Alimentar no Contexto da Pandemia da Covid-I9 no Brasil. 202I. Disponível em: $<$ http://olheparaafome.com.br/VIGISAN_Inseguranca_alimentar.pdf $>$. Acesso em: I2 abr. $2 \mathrm{O} 2 \mathrm{I}$. 
PRATES, I.; BARBOSA, R. J. The impact of COVID-I9 in Brazil: labour market and social protection responses. The Indian Journal of Labour Economics, v. 63, n. SI, p. 3I-35, out. 2020.

PRATES, I.; GUICHENEY, H. Sem diretrizes para o ensino remoto e a volta às aulas, governo Federal repete na educação a tragédia da saúde. Milhões de crianças ficaram em casa sem atividades escolares e os mais pobres perderam até 50 dias letivos de aula. Rede de Políticas Públicas \& Sociedade, Boletim 22, 28 ago. 2020. Disponível em: < https://redepesquisasolidaria.org/boletins/boletim-22/sem-diretrizes-para-o-ensinoremoto-e-a-volta-as-aulas-governo-federal-repete-na-educacao-a-tragedia-da-saudemilhoes-de-criancas-ficaram-em-casa-sem-atividades-escolares-e-os-mais-pobresperderam-a/>. Acesso em: 20 abr. 202I.

RANZANI, O. T. et al. Characterisation of the first 250,000 hospital admissions for COVID-I9 in Brazil: a retrospective analysis of nationwide data. The Lancet Respiratory Medicine, v. 9, n. 4, p. 407-4I8, abr. 202I.

RIBEIRO, K. B. et al. Social inequalities and COVID-I9 mortality in the city of São Paulo, Brazil. International Journal of Epidemiology, p. I-II, 28 fev. 202I.

SADER, E. Quando novos personagens entraram em cena: experiências, falas e lutas dos trabalhadores da Grande São Paulo(I970-80). Rio de Janeiro: Paz e Terra, I988. 